\title{
Grammatical understanding, literacy and text messaging in school children and undergraduate students: a concurrent analysis
}

\author{
Clare Wood \\ Coventry University \\ Nenagh Kemp \\ University of Tasmania \\ Sam Waldron \\ Coventry University
}

\section{Author Note:}

Clare Wood, Department of Psychology and Behavioural Sciences, Coventry University;

Nenagh Kemp, School of Psychology, University of Tasmania; Sam Waldron and Lucy Hart, Department of Psychology and Behavioural Sciences, Coventry University.

This research was supported by a grant from the Nuffield Foundation (EDU/38640).

We would also like to acknowledge the support and assistance of: Lucy Hart, Neelam Nagra, Christopher Reynolds, Mary Thompson, Viki Petkova, Jonathan Linton, and Sapna Halai, as well as the support of the participants and schools involved.

Correspondence concerning this article should be sent to Clare Wood, Department of Psychology and Behavioural Studies, Coventry University, Priory Street, Coventry, CV1 5FB. Email: c.wood@ coventry.ac.uk. 


\title{
Grammatical understanding, literacy and text messaging in school children and undergraduate students: a concurrent analysis
}

\begin{abstract}
Recent research has demonstrated that use of texting slang when text messaging does not appear to impact negatively on children and young people's literacy and may even benefit children's spelling attainment. However, less attention has been paid to the impact of text messaging on children's and young people's understanding of grammatical forms. This study examined the interrelationships between 243 children and undergraduate students' grammatical violations made when text messaging and their performance on assessments of spoken and written grammatical understanding, orthographic processing and conventional spelling ability. The children were found to make significantly more capitalisation and punctuation errors, and to use unconventional punctuation more frequently that the adults, when the length of their messages was taken into account. For the primary and secondary school children there was no relationship between the tendency to make grammatical violations when texting and their understanding of conventional grammar or orthography. For the young adult sample, there was some evidence of an association between the tendency to make capitalisation and punctuation errors when texting, and poorer performance in selecting the grammatically correct orthographic representation of a pseudoword. This relationship remained after controlling for individual differences in undergraduates' IQ and spelling ability. Overall, there is little evidence that ungrammatical texting behaviour is linked to grammatical understanding or knowledge of orthographic representations of language in children. However, there is some evidence that young adults' violation of grammatical conventions when texting may be linked to limited understanding of grammatically-related orthographic conventions.
\end{abstract}

Keywords: text messaging, SMS, grammar, spelling, language 


\section{Grammatical understanding, literacy and text messaging in school children and undergraduate students: a concurrent analysis}

\section{Text Messaging and Written Language Skills}

Text messaging (SMS use) continues to increase in popularity: the number of texts sent worldwide was estimated at 7.8 trillion for 2011 , with a further 1.8 trillion predicted for 2012 (Portio Research, 2012). Mobile phone use and text messaging now form part of many young people's everyday activity. In the UK, Ofcom (2011a, 2012a) has found that the number of text messages sent by children rose in 2012, with 8- to 11-year-olds sending about 41 messages per week (up from about 27 in 2009-2011) and 12- to 15-year-olds sending about 193 (up from about 113 in 2009-11). Teenagers and young adults, too, are keen users of text-messaging, sending an average of 50 texts per week (Ofcom, 2012b). There has also been a rapid rise in smartphone ownership, now at $1 \%$ for 5 - to 7 -year-olds, $15 \%$ for 8 - to 11 year-olds, 62\% for 12- to 15-year-olds, and 66\% for 16- to 24-year-olds (Ofcom, 2012a,b), although ownership of phone technology is relatively unaffected by socioeconomic status. This trend is noteworthy, as smartphone users make more calls and send more texts than those using other phone types (Ofcom, 2011b).

Text messaging is characterised by an abbreviated written form, originally used because of the character restrictions imposed by phone companies; it has persisted and developed into a form of technologically-mediated discourse. It is similar, if not identical, to other popular forms of computer-mediated discourse such as instant messaging, and the language forms observed on social networking sites (e.g. 'wall posts' in Facebook) and microblogging sites such as Twitter, which also have character restrictions. Thurlow (2003, p. 1) has suggested that texting is "reinventing conventional linguistic and communicative 
practices". This linguistic form plays with orthographic conventions, relies on shared social references, and expresses intended emotional states through the use of emoticons.

However, there has been concern about the impact that texting may have on children's and young people's use of formal written English. This is because most texting abbreviations (or 'textisms' as we term them here) focus on unconventional orthographic representations, which have intact phonological representations, such as 2 morrow for tomorrow. Abbreviations and acronyms are not new additions to written language (Baron, 2003). However, rather than celebrating the creativity evident in the evolution of texting slang, the popular media have focussed on the assumed negative impact that the use of such language must inevitably be having on language in general, and children's and young people's literacy skills in particular (e.g., see Crystal, 2008; Wood, Kemp, \& Plester, 2014). For example, Thurlow's (2006) critical discourse analysis of media accounts of computer-mediated discourse (which included mobile phone texting) revealed an overwhelmingly critical portrayal, which equated its use with declining morality as well as literacy. An online article by Woronoff (2007) sums up the media 'thesis' most clearly:

There is no problem among older people because their spelling skills are more established. Children are more prone to commit errors because they have read less, and prefer to play games, or watch TV, etc. ... Texting has come along with a flourish, making a big impact among them. This habit forming menace can influence kids to spell incorrectly or get confused about the correct usage. We should not tolerate these activities, else it might endanger their progress. ...It is likely that it might affect much of their ability to spell, since their minds are in the formation stage. As a consequence of such concerns, recent research has considered how knowledge and/or use of textisms might be related to 'traditional' literacy skills. In the first of these studies, Plester, Wood, and Bell (2008) assessed knowledge of textisms via a simple 
translation task and found that that children aged 10-12 years who tended use more textisms when converting a standard English sentence into a text message had better verbal reasoning and spelling ability. Similarly, Plester, Wood, and Joshi (2009) asked 10-12-year-olds to construct text messages in response to hypothetical situations, and found that those who used more textisms tended to have better word reading, vocabularies and phonological awareness. Plester et al. theorised that the reason for this finding was that decoding and creating most textisms requires a certain level of phonological awareness, a skill known to underpin successful literacy acquisition. They therefore expected to find that the relationship between textism use and reading ability would disappear once individual differences in phonological awareness had been taken into account. However, they found that textism use could still predict unique variance in reading ability after controlling for age, short-term memory, phonological awareness, vocabulary and length of time the children had owned a mobile phone. The pattern of results from these studies has been supported by Kreiner and Davis (2011), who found that knowledge of abbreviations was positively correlated with spelling scores but frequency of texts was not. This suggests that it is not the quantity of messages that are sent which is important, but the content of messages with respect to levels of texting slang used.

These early studies suggested that not only was there no evidence of a negative association between literacy outcomes and knowledge of textisms, but that textism use might 'add value' to literacy development in unexpected ways. However, these researchers relied on contrived, paper-based tasks as a way of eliciting textism knowledge. More recent studies have looked specifically at children's actual texting behaviour, but the conclusions from these papers are the same. For example, Coe and Oakhill (2011) found no significant differences between good and poor readers aged 10 to 11 years in terms of the number of text messages sent and received. Good readers did, however, use significantly more textisms in their 
messages. It is suggested that better readers may be able to use multiple registers more easily and possibly have better metalinguistic skills. Similarly, Veater, Plester, and Wood (2011) examined textism use by dyslexic and typically-developing children. These authors found that the proportion of textisms used did not differ significantly between the two groups of children, but the dyslexic children tended to use fewer phonetically-based textisms, and for these children there was no association between literacy skills and textism use. As children with dyslexia are characterised by difficulties processing phonological information, their avoidance of phonetically-based textisms is not surprising.

The central claim of the media thesis about text messaging and literacy development is a strong one: namely that textism use causes problems with literacy development in children and young people. Although the concurrent data reviewed so far do not suggest that there is any negative impact, to address such issues of direction of causality, data need to be collected over time, and two of the most recent studies in the area have done this.

Wood, Meacham, Bowyer, Jackson, Tarczynski-Bowles, and Plester (2011) collected longitudinal data (over the course of an academic year) from 119 8- to 12-year-olds who owned their own phones. This study showed that, similar to concurrent studies, textism use at the beginning of the year could predict spelling ability at the end of the year, after controlling for individual differences in age, verbal IQ, phonological awareness and the children's spelling ability at the beginning of that year. In contrast, spelling ability at the beginning of the year was unable to explain growth in the use of textisms when messaging. It seems that textism use may be contributing in unanticipated ways to the development of children's understanding of conventional spellings, and that the relationship between textism use and spelling ability is unidirectional, rather than reciprocal.

This result raises the practical question of whether mobile phones may be used as a form of educational technology for supporting literacy development, given the high status 
placed on phones by children and the children's motivation to use them on a regular basis. To address this issue, Wood, Jackson, Hart, Plester, and Wilde (2011) conducted a randomised, controlled trial intervention study in which they gave mobile phones to 9- to 10year-olds who did not previously own them, and enabled these phones for text messaging at weekends and during the half-term holiday. The children in the phone ownership group did not show significantly improved literacy skills compared to children in the control group over the course of a 10 -week period. However, within the phone group, textism usage was able to account for a significant amount of variance in post-test spelling scores over this short period, again after controlling for IQ and spelling ability at the beginning of the term.

So with respect to children, we can argue that literacy skills appear to be largely unaffected by mobile phone ownership or the number of messages sent or received. Yet, textism use does appear to contribute to the development of spelling ability in particular. However, children's representation of phonology and orthography is likely to be different to that of older skilled readers, and experimental studies of exposure to misspelled words has suggested that young adults' spelling performance is more likely to be disrupted by exposure to misspelled forms than that of children (Dixon \& Kaminska, 2007). Less research into texting has been conducted with older populations, and most of that with university students. However, the findings that have been reported show far more mixed relationships between texting behaviour and literacy scores than have been observed in child samples. Some researchers have seen no significant association between undergraduates' conventional literacy abilities and their use of textisms (Kemp, 2010) or their self-reported frequency of sending text-messages (Massengill Shaw, Carlson, \& Waxman, 2007). Similarly, students self-identified as users or non-users of textese did not differ significantly on tests of word reading, reading fluency, or spelling (Drouin \& Davis, 2009). However, some positive links between other aspects of adult texting behaviour have been reported. US students' self- 
reported text-messaging frequency was positively associated with spelling skill and reading fluency (Drouin, 2011), and Australian students' textism reading accuracy and message composition speed were positively correlated with their conventional spelling and reading scores (Kemp, 2010). Some negative relationships have also been noted. Rosen, Chang, Erwin, Carrier, and Cheever (2010) found that among young US adults with some or no college education (but not among those with a college degree), the frequent use of textisms was linked to poorer scores on a formal writing task. De Jonge and Kemp (2012) reported that in Australian undergraduates, frequent text-messaging, as well as greater use of textisms and of more varied textism types, were all associated with poorer performance on spelling, reading, and nonword reading assessments. Even within samples there are mixed results, depending on the literacy tasks used. Naturalistic textism use has been found to correlate negatively with reading and spelling, but not reading fluency or vocabulary in US students (Drouin \& Davis, 2012), and negatively with spelling (but not reading) in Canadian students and negatively with timed nonword reading (but not spelling) in Australian students (Grace, Kemp, Martin, \& Parrila, 2013).

Taken together, these data suggest that results obtained with children may not extend to young adult samples. However, the literature is still quite limited in this area and longitudinal data are needed to examine the issue of causality for this population.

\section{Text Messaging and Understanding of Grammar}

One area of written and spoken language development that has yet to be extensively examined is the impact of text messaging on grammatical understanding. Text-messages often show transgressions of grammatical conventions, such as the misspelling of words and parts of words that are determined by grammar (e.g., using ur for your or you're, or respelling the $-s$ inflection in friendz) and the omission of capitals and apostrophes (e.g., im well). Numerous child and adult studies have included counts of such categories (e.g., Drouin \& 
Driver, 2012; Plester et al., 2009; Rosen et al., 2010), and Tagliamonte and Denis (2008) looked at the grammatical construction of teenagers' instant messages (IM). However, few studies have focussed specifically on the inter-relationships between texting behaviour, understanding of written or spoken grammar and spelling skills. In fact, the only one that has been published to date was a survey study conducted by Cingel and Sundar (2012), which asked 228 US Grade 6-8 students (aged 10-14 years) to complete a grammar assessment and a questionnaire about their texting behaviour. Textism use was assessed by asking the children to look at the last three messages that they sent and received and to count and classify the 'adapations' used in each message into one of five types: abbreviations / initialisms; omission of non-essential letters, substitution of homophones, punctuation adaptations, and capitalisation adaptations. The authors found that the average number of reported adaptations predicted significant variance in performance on the grammar test after the students' grade level had been accounted for (4.7\%), and that the direction of association was negative. However, there are a number of methodological weaknesses in this study. The categorisation of the textisms was done by the children and there was no mechanism to enable the researchers to verify that the messages had been correctly coded. The classification of the adaptations was quite simplistic, and not all the categories relate directly to grammatical understanding. This weakens any arguments made about whether these data are indicative of a progressive lack of understanding of standard grammatical convention. That is, 'word adaptations' (abbreviations, letter omissions and homophones) were found to be the textism type negatively related to grammatical performance. Since this category captures spelling violation rather than grammatical issues, it is not clear why the use of alternative spellings would impact on grammatical understanding. It should also be noted that there were no baseline data taken about these children's grammatical ability. It is also not possible to infer this from the grammar test used, which was intended for use with older 
(Grade 9) children, but adapted for this sample. Although the authors were very careful not to overstate the significance of these initial results, stating clearly that "due to the

correlational nature of the research, causation cannot be inferred from these results" (p. 1318) the findings of this study were widely reported in the international media as demonstrating that texting undermines children's understanding of grammar.

\section{Rationale}

There is a need for research which examines the associations between text messaging and grammatical understanding in both young adult and child populations, and does so in a way which can factor in individual differences like IQ and uses standardised assessments of spelling and grammar to address this question. This paper therefore reports on a more comprehensive study which was concerned with whether or not there is any evidence of a concurrent relationship between the tendency to make grammatical violations text messaging, and participants' actual levels of grammatical understanding (spoken and written). We focused on the use of textisms when texting via mobile phones because of the continued increase in levels of text messaging worldwide year on year. As mobile devices are increasingly used to access social networking and microblogging sites, it seems reasonable to suggest that the way in which text messages are composed on a mobile phone is likely to be typical of the text composition used via these devices on sites like Facebook and Twitter.

Three age groups were recruited to consider whether there were different patterns of relationships between variables in the early stages of literacy development (primary school), compared to the intermediate stages (secondary school) and the skilled/consolidated (adult) stages. Measures of spelling and orthographic processing were also considered with respect to this research question, as theoretically there is good reason to believe that these skills may impact on the ways in which individuals compose text messages. Awareness of the phonological structure of words, and of orthographic patterns, is crucial for conventional 
literacy development, including spelling (e.g., Berninger, Abbott, Nagy, \& Carlisle, 2010). Phonological awareness is also important for creating and deciphering the many textisms with a phonetic basis (e.g., thanx for thanks; 2 for to). However, the spelling of other textisms requires the manipulation and sometimes the violation of these orthographic conventions (e.g., the lack of vowels in txt msg or the combination of letters and numbers in 2day). Since there is evidence for positive links between textism use, phonological awareness and spelling skill in children (e.g., Plester et al., 2008, 2009), it may be that children who are most sensitive to orthographic patterns are most able to 'play' with them to create and use textisms. The negative or non-significant links between textism use, phonological awareness and spelling skill in adults (Drouin \& Driver, 2012; Grace et al., 2013; Kemp, 2010) suggest that these relationships might be quite different once spelling is consolidated, and need further investigation.

The nature of the English spelling system means that phonological and orthographic conventions often interact with conventions about morphology, including grammar (Nunes, Bryant, \& Bindman, 1997). We outline three main ways that texting could conceivably harm grammar, and which could potentially explain the various grammatical transgressions that have been observed in adults' and children's text messaging:

i. $\quad$ Spelling of individual words: In English, the spelling of many words is partly determined by morphology, which is one aspect of grammar. For example, some word suffixes (inflections) are always spelled in the same way despite differences in pronunciation, to reflect their shared grammatical structure (e.g., the -ed inflection of mixed, stirred, and kneaded). Children often start spelling these patterns just as they sound (stird for stirred, keez for keys) and have to learn grammar-based spelling consistencies (Kemp \& Bryant, 2003; Nunes et al., 1997). Further, grammar-based spelling can distinguish words which sound the same but 
which differ in grammatical status, such as the spelling of the final $/ \mathrm{ks} /$ sound in the plural noun tacks and the singular noun tax. Textisms are commonly phonetic representations of words (e.g., hafta, pix, frendz), and therefore young children who text message frequently may find it difficult to learn these grammar-based consistencies, and older children and adults might not remember to use them in formal writing.

ii. Spelling of word combinations: In speech, the pronunciation of many words is reduced and words are combined to create common elisions, such as gonna, hafta, would've, and you're. When text messaging, people are often exposed to phonetic spellings of these word combinations, and children may find it difficult to learn, and adults to remember, that in conventional writing, these forms need to be written in full, as in going to, would have (not would of) or abbreviated appropriately, as in you're, (not your).

iii. Correct use of orthographic and punctuation conventions: In text-messaging (as in other forms of digital communication), it is common to omit capitalisation of sentence-initial words, proper nouns, and the subject pronoun I (De Jonge \& Kemp, 2012; Rosen et al., 2010; Varnhagen et al., 2009). It is also common to omit punctuation, to use multiple exclamation marks or question marks, or to use symbols such as emoticons, often in place of conventional punctuation (De Jonge \& Kemp, 2012; Provine, Spencer, \& Mandell, 2007; Rosen et al., 2010). Children and adults who become used to the non-regulated use of capitalisation and punctuation in text messages may become less focused on using them correctly in formal writing.

\section{Method}

\section{Participants}


Participants were recruited from three age categories, who came from three primary schools, three secondary schools and and a university (total $\mathrm{N}=243$ ) in the English West Midlands. There were 89 primary school children (29 from Year 4 and 60 from Year 5), with a mean age of 9.9 years (range 8.6-10.9), with 42 males and 47 females. These participants had a mean full IQ score of 103.2 (100.0 for performance IQ and 103.8 for verbal IQ, as measured using the Wechsler Abbreviated Scales of Intelligence - see Test Battery). There were 84 secondary school children (46 from Year 7, 20 from Year 8 and 18 from Year 10), with a mean age of 12.8 years (range 11-15.9), with 52 males and 32 females. These participants had a mean full IQ score of 98.4 (performance $\mathrm{IQ}=98.2$ and verbal $\mathrm{IQ}=95.6$ ). There were 70 adult participants; 19 males and 51 females, with a mean age of 20.8 years (range 18 -30). These participants had a mean full IQ score of 105.9 (performance IQ= 106.5 and verbal=104.1). All but one of the primary school children and six of the undergraduates had English as a first language. All participants owned their own mobile phones and $19.7 \%$ of children and $34.3 \%$ of adults reported consistent use of predictive texting when text messaging. Seventy percent of adults and $45.7 \%$ of children owned smart phones with qwerty keyboards and the remainder owned phones with a traditional number-pad based keypad.

\section{Test Battery}

Test of Receptive Grammar II (TROG II; Bishop, 2003). This measure was included as a widely used and validated, standardised assessment of children's and adults' understanding of spoken grammar. This required participants to pick one picture from a choice of four that corresponded to a grammatical sentence that the researcher said aloud. This task was administered individually. The sample alpha for this measure was 0.922 . Note that sample alphas (Cronbach's) for all measures are reported rather than from previous reports (e.g., during standardisation or in other studies) as a point of good practice. This is 
because internal reliability is a feature of a test when used with a specific sample and so cannot be assumed to be stable (see Thompson, 2003, for a discussion). Standardised scores (mean 100, SD 15) were used in the analyses.

Pseudoword Orthographic Choice Task (based on Mitchell, Kemp, \& Bryant, 2011). This task tests the ability to use the grammatical structure of a sentence to select the one grammatically appropriate spelling for a pseudoword that is presented in two identicalsounding ways that are both orthographically plausible. There were 64 pseudowords in all, presented in eight different categories of grammatical status (see Appendix), for each of which there is a spelling rule. For example, plural nouns generally end in $s$, and singular nouns generally do not. Thus, the sentence I have two prex / precks cues the plural noun spelling precks, whereas I like this preeze / prees cues the singular noun spelling preeze.

Participants were given 64 printed sentences. For each sentence, one form of a pseudoword (e.g., verb infinitive) was represented by three dots (so as not to bias participant spelling), and a printed choice of two spellings was given for a different form of the pseudoword (e.g., third-person singular verb). The researcher read aloud each sentence, including the missing form and the final form of the pseudoword, and asked participants to circle which pseudoword spelling of the final form they thought was the most appropriate. An example printed sentence is I ... my lawn any time, but he voes / voze his lawn only when it is sunny, with the researcher pronouncing the missing base form as "voe". Participants received one point for each correctly identified word. This task was administered to small groups of participants at a time (between 5 and 20). The sample alpha for this measure was 0.882 . As this measure is not a standardised test, raw scores were used in the analysis.

Wordchains (Guron, 1999) with Articulatory Suppression. The Wordchains task was used here as a measure of orthographic processing ability. The task was administered according to the standardised instructions but participants were also required to say the 
syllable 'la' repeatedly during the activity so that the contribution of phonological processing was minimised during the task (articulatory suppression). The task required participants to look at a series of letter strings which comprised three words presented together without any spaces. Participants were asked to mark the boundaries between the words correctly as quickly as possible. One hundred and twenty of these 'wordchains' were presented to the participants and they were given one point for each chain that was correctly segmented in three minutes. The sample alpha was 0.970 .

Wechsler Abbreviated Scales of Intelligence (WASI; Wechsler, 1999). This standardised assessment comprised four subtests (vocabulary, similarities, block design and matrix reasoning) which together produced a measure of the participants' general cognitive abilities (expressed as an IQ score), as well as verbal and non-verbal (performance) IQ. As with the other standardised assessments, standardised IQ scores were used in the analysis (mean 100, SD 15). The sample alpha for each of the four subtests was as follows: Vocabulary 0.903; Similarities 0.847; Block Design 0.847; Matrix Reasoning 0.890.

Wide Range Achievement Test IV (WRAT IV; Wilkinson \& Robertson, 2006) Spelling Subtest. This task is a standardised assessment of children's and adults' spelling ability. As with the TROG II, this task also provides an indication of how typical a sample of participants is relative to age-related norms.. This test was administered in a group setting. The sample alpha was 0.939 .

\section{Coding the Grammatical Violations in Text Messages}

Participants were asked to copy out all the mobile phone text messages that they had sent within a recent two-day period, exactly as they had written them. The messages were taken from a period which predated their participation in the study, so that this factor did not influence the way in which participants constructed their messages. The text messages were analysed and coded for the number and nature of grammatical violations that were observed. 
Each word was coded for as many mistakes as occurred. For example, im would be coded as both missing contraction apostrophe and i for I (see Table 1). There were three broad categories of text violation noted: unconventional orthographic forms (e.g., using symbols such as emoticons in place of traditional punctuation such as question marks), punctuation and capitalisation errors (using standard punctuation incorrectly), and word-based grammatical errors (e.g., writing hafta for have to, or they is for they are). The number of times these types of error occurred was then divided by the total number of words used in all the messages sampled, so that these values were represented as proportional to the length of the messages used. Although we use the term "error", we were not able to distinguish errors of carelessness or ignorance from deliberate, often playful, violations of conventional English writing.

Table 1 about here.

\section{Results}

Table 2 presents the summary statistics for the participants split by age group for each of the key measures in the study. As can be seen, all three groups show performance within the average range for their age on the standardised measures (i.e., average group scores within 15 points either side of the standardised mean of 100). The age at which the participants first received their mobile phone was found to decrease across age groups, with the adults reporting receiving their first phone around the age of 12-13 years, and the primary school children receiving their phones around the age of seven. The number of messages sent, on average, each day was found to be highest in the adult group and lowest in the primary group, and are consistent with self-reported levels of texting found in previous research (e.g., see Wood et al., 2014). Of particular interest is the question of whether there are age-related differences between the three groups in the level and nature of grammatical violations observed in their text messages, and their performance on the orthographic choice 
task, used here as an assessment of written grammatical understanding. Looking at the levels of unconventional orthographic forms used across the three age groups, we can see that the tendency to use 'alternative' forms of punctuation develops somewhat with age, with the secondary school children showing the greatest tendency to play with these conventions. This is consistent with a view of the use of such forms as a creative and potentially positive form of orthographic understanding.

Group differences in the tendency to make the various types of grammatical violations were examined using non-parametric analyses (Kruskal Wallis) rather than ANOVA, as the range of scores observed in the children's groups was much larger than that observed in the adult group. The analyses showed that there was no significant difference between the three age groups with respect to the proportion of word-based grammatical errors observed when texting $\left(\chi^{2}(2)=3.383, p=.184\right)$. However, there was a significant main effect of group on punctuation and capitalisation errors $\left(\chi^{2}(2)=89.225, p<.0005\right)$; Mann-Whitney post hoc comparisons revealed that the adults made fewer errors than both the primary $(U=597.5$, $p<.0005)$ and secondary school children $(U=848.0, p<.0005)$. There was also a significant main effect of group on participants' use of unconventional orthographic forms $\left(\chi^{2}\right.$ $(2)=39.004, p<.0005)$, with the primary school children using unconventional orthographic forms less often than both the adults $(U=1449.0, p<.0005)$ and the secondary school children $(U=2209.0, p<.0005)$.

The groups of participants also differed significantly in terms of the number of texts sent per day $\left(\chi^{2}(2)=81.347, p<.0005\right)$, with the adults sending significantly more than the primary and secondary school children $(U=783.5, p<.0005$ and $U=828.5, p<.0005$ respectively). Similarly, there was a main effect of age group on the age at which participants reported receiving their first phone $\left(\chi^{2}(2)=135.004, p<.0005\right)$; the adult 
participants were significantly older than both the primary and secondary school children ( $U=116.5 p<.0005$, and $U=442.5, p<.0005$ respectively).

\section{Primary School Children}

Table 3 presents the correlation matrix representing the zero order correlations between the variables in the study, for the primary school children. Performance on the orthographic choice task correlated significantly with performance on the other orthographic processing measure (Wordchains) and the standardised measures of spelling and grammatical understanding. This suggests that the orthographic choice task is a valid measure of the children's ability to make grammatically-based, appropriate written word choices based on sentence context. Moreover, it demonstrates that within this age group there is a strong degree of interrelatedness between these four very different measures of 'literacy', irrespective of whether the measures are tapping decoding processes (as in the TROG and the orthographic processing task) or encoding processes (as in the spelling and orthographic word choice tasks). The three categories of grammatical violation when text messaging were not significantly correlated with each other.

Table 3 about here.

In terms of the primary research question, however, we can see that the three categories of grammatical violations in the children's spontaneous text messages are not significantly correlated with IQ, levels of grammatical understanding, spelling achievement or orthographic processing ability. In other words, contrary to popular concerns, there does not appear to be any sign of a significant negative relationship between grammatical errors made when texting and primary school children's understanding of standard grammar or knowledge of conventional spelling.

\section{Secondary School Children}


Table 4 shows the correlations between variables for the children in the secondary school sample. For these children, we can see that performance on the orthographic choice task is once again significantly related to understanding of spoken grammar and performance on the standardised test of spelling ability. In other words, there is evidence to support its validity as a measure which taps both grammatical understanding and understanding of spelling conventions. If we also consider these literacy variables in terms of encoding versus decoding tasks we can see that the two encoding variables are still significantly correlated with each other but the two decoding measures are no longer related.

For the different levels of grammatical violation, the only significant relationship is between punctuation and capitalisation errors and use of unconventional orthographic forms, and that relationship is negative. Use of unconventional orthographic forms was also positively related to the children's IQ. As with the primary school children's data, use of the three different types of grammatical violation was not observed to be related to performance on the TROG, spelling ability, or performance on either of the orthographic measures.

Table 4 about here.

\section{Undergraduates}

For the undergraduate sample, the correlations reveal a full separation between different literacy domains. Whilst there are significant relationships between the two grammar variables and between the two 'print processing' variables (spelling and orthographic processing), there is no longer any relationship between the measures we classed as 'encoding' variables (orthographic choice and spelling) and 'decoding' variables (TROG and orthographic processing). We can also begin to see some evidence that the tendency to make grammatical violations when texting is related to the ability to select the most grammatical orthographic representation of an unknown word. As the tendency to make punctuation and capitalisation errors increased, the participants' scores on the 
orthographic choice task decreased. However, a negative correlation was also observed between the tendency to make punctuation and capitalisation errors and participants' IQ scores.

Table 5 about here.

A hierarchical multiple regression analysis was conducted to examine the extent to which the punctuation and capitalisation error scores could explain a significant amount of variance in the undergraduates' performance on the orthographic choice task, after controlling for individual differences in IQ and spelling ability (as per the original research question). Spelling ability and IQ scores were entered at the first step in the model as control variables whose influence on the dependent variable needed to be taken into account before looking at the contribution of texting. These two variables together explained $21.9 \%$ of the variance in performance on the orthographic choice task $\left(R^{2}=.219, F(2,67)=9.389, p<.0005\right)$. The tendency to make punctuation and capitalisation errors was then entered in the second step of the regression. The results showed that this variable could account for a further $8.0 \%$ of the variance $\left(R^{2}\right.$ change $=.080, F$ change $\left.(1,66)=7.528, p=.008\right)$. This suggests that IQ and spelling ability only partially mediate the relationship between texting-based grammatical violations and orthographic choice scores.

Table 6 about here.

\section{Discussion}

The results indicate that for children there is no evidence that the tendency to make grammatical violations when text messaging is related to the actual understanding of either grammar or orthography. For undergraduates, there is some evidence of a link between the tendency to make punctuation and capitalisation errors when texting and understanding of written grammar. This is partially explained by individual differences in IQ and spelling ability, but the association remains even after controlling for the influence of these variables. 
The undergraduate data raise the interesting question of why, given the relatively low levels of violation being made in this group overall, young adults' violation of the rules of punctuation and capitalisation specifically is particularly associated with disruption to their representation of grammatically determined spellings. The simplest explanation for this finding is a statistical one. That is, Table 2 shows that this particular type of violation was the most common one for this age group, with the greatest variation in scores. This specific correlation is therefore possibly an artefact of these statistical features of the variable, rather than a cross over influence from making punctuation / capitalisation errors to being sensitive to grammatically-influenced word spellings, per se. So, if we accept that performance on the punctuation and capitalisation variable is simply the most sensitive measure of grammatical violation for the young adult participants, then we can suggest the tendency to make grammatical violations when texting (in general) may erode these participants' appreciation of grammatically-based spelling consistencies in writing English. The fact that this relationship remained after controlling for individual differences in IQ and conventional spelling ability shows that this not simply a matter of a lack of intelligence or academic ability: there does seem to be an independent association between the two variables. As with the previous concurrent studies, we cannot be confident as to whether the violations are leading to the problems in recognising grammatically appropriate spellings, or whether understanding of grammatically appropriate spellings contributes to the tendency to make grammatical violations when texting. Longitudinal data are needed to determine the direction of this relationship, and also to consider the important question as to whether texting is linked to the development of grammatical understanding over time.

The different patterns of association between the child and young adult cohorts suggest that skilled readers (with relatively consolidated representations of grammar and orthography) may be more vulnerable than children to damage to their orthographic 
representations of grammar as a result of poor attention to grammar and orthography when texting. Dixon and Kaminska (2007) suggested that this may be because children's representations of grammar and orthography are more flexible and also perhaps not so well integrated as those of adults, and that the production of incorrect grammar and spelling is therefore less likely to reflect the children's representations of those forms in memory. For adults, the receptive and productive language systems may be better integrated, as could be their representations of spelling, grammar and orthographic conventions. The patterns of correlation between the various literacy variables suggest that the primary school children had very flexible, fully integrated literacy processing systems, as encoding and decoding processes are interrelated and cut across different domains of literacy activity. In the secondary school cohort we see a rather less integrated pattern of associations. With the undergraduates we see that encoding and decoding processes are not so well integrated across domains, but performance within domains is preserved. Therefore it seems likely that this progressive specialisation of encoding and decoding processes within domains, coupled with a lack of flexibility, may contribute to the link observed between poor attention to grammar and punctuation when texting and grammatical processing (as we have defined it here). Longitudinal research which examines the relative dissociation of productive and receptive measures of grammatical violation in the context of text messaging may provide some insight into this type of potential explanation.

We would argue, however, that it is important to recognise the distinction, apparent in our data, between the playful use of unconventional orthographic forms and the occurrence of errors which are more likely to be linked to problematic understanding of grammar and punctuation. Especially as their conventional literacy skills become more consolidated, young people may use textisms quite deliberately and often playfully, to reduce the length of their messages (Taylor \& Vincent, 2005), to add expression and emotion (Dresner \& Herring, 
2010), or to show their membership of a social group (e.g., Lewis \& Fabos, 2005). Their first thought is presumably not of grammatical correctness, but of the various other motivations for using alternative spellings in text messages. In the primary school data set, there is little evidence of the more playful use of unconventional orthography. By secondary school such use is more common, but it is also inversely related to the tendency to make punctuation and capitalisation errors when texting. With the undergraduate data we see there is the negative relationship between playful use of unconventional orthography and punctuation errors as before, but we see a positive relationship between word-based grammatical errors and use of unconventional orthography. This suggests that young adults may be making word-based errors deliberately, rather than out of ignorance of grammatical rules. The concern is, then, that for some young adults at least, some of these playful violations have the potential to erode their orthographic understanding of English. Since our adult participants were all university students, they may have more exposure to textisms than older adults, who might text less often, and use fewer textisms (Ofcom, 2012b). Further, our undergraduate participants are likely to have had an overall higher level of literacy skills than a sample of adults drawn from the wider population. Adults who have less consolidated literacy abilities to start with may be more vulnerable any influence of textisms on spelling, as suggested by Rosen et al.'s (2010) comparisons of formal writing samples in participants with and without a completed tertiary education. However, it is also important to flag the lack of any other relationships between grammatical violations when texting and performance on measures of spelling, orthographic processing and understanding of spoken grammar.

\section{Conclusions}

Previous research with texting and literacy has focused mainly on violations of the spelling/representation of individual words in text messages, and the relationship between such violations and other conventional literacy skills, usually spelling and reading. The 
present study focused on violations of grammatical conventions, and links with spelling and reading, but also with knowledge of grammar, and IQ. Children at primary and secondary school level, as well as adults at university, all used textisms that violated grammatical conventions, including unconventional orthographic forms, word-based grammatical errors, and errors of punctuation and capitalisation. It is likely that these grammatical transgressions represented a mix of playful, deliberate textisms that happened to violate conventional grammar, and instances of careless or ignorant grammatical errors. The comparison with literacy-related skills helps to reveal whether the production of such grammatical errors should be seen as a matter of concern.

We found that the text messages of children at both primary and secondary school were rife with grammatical violations. However, the children's tendency not to use conventional grammatical rules in messages was not related to their reading, spelling, or grammatical skills. This goes against the concerns expressed in the popular media. Young adults made fewer grammatical violations in their messages than did children (if the proportion of words is considered). The one negative relationship between grammatical violations and literacy performance was partially mediated by IQ and spelling ability. Future researchers should explore whether different patterns are seen with adults of a broader range of ages, whose literacy skills may be less well consolidated to begin with.

At this point our interpretations are mainly speculative. Nevertheless, the main conclusion seems to be that unlike spelling transgressions in texting, which at least in children are positively linked to more conventional spelling and reading skills, grammatical transgressions in texting are not positively linked to conventional skills in reading, spelling, or grammar. However, despite media concerns, it appears that for children at least, making frequent grammatical violations when writing text messages is not related to any apparent declines in grammatical knowledge. For adults there is some evidence of an association, but 
it is an isolated one in the context of a range of other language variables which had no relationship to grammatical violations when texting. Therefore, as before, we feel that the case for the negative impact of texting on language skills may have been overstated. 


\section{References}

Baron, N.S. (2003). Language of the Internet. In A. Farghali (Ed.), The Stanford Handbook for Language Engineers (pp. 59-127). Stanford, CA: CSLI Publications.

Berninger, V.W., Abbott, R.D., Nagy, W., \& Carlisle, J. (2010). Growth in phonological, orthographic, and morphological awareness in Grades 1 to 6. Journal of Psycholinguistic Research, 39, 141-163. doi 10.1007/s10936-009-9130-6

Bishop, D. (2003). Test for reception of grammar (TROG-2). London: Pearson Assessment.

Cingel, D.P. \& Sundar, S.S. (2012). Texting, techspeak, and tweens: The relationship between text messaging and English grammar skills. New Media and Society, 14, 1304-1320.

Coe, J.E.L., \& Oakhill, J.V. (2011). 'txtN is ez $\mathrm{f} \mathrm{u} \mathrm{no} \mathrm{h2} \mathrm{rd':} \mathrm{the} \mathrm{relation} \mathrm{between} \mathrm{reading}$ ability and text-messaging behaviour. Journal of Computer Assisted Learning, 27, 417. doi: 10.1111/j.1365-2729.2010.00404.x

Crystal, D. (2008). Txtng: frNd or foe? The Linguist, 47(6), 8-11.

De Jonge, S., \& Kemp, N. (2012). Text-message abbreviations and language skills in high school and university students. Journal of Research in Reading, 25, 49-69. doi: 10.1111/j.1467-9817.2010.01466.x

Dixon, M., \& Kaminska, Z. (2007). Does exposure to orthography affect children's spelling accuracy? Journal of Research in Reading, 30, 184-197. doi:10.1111/j.14679817.2007.00337.x.

Dresner, E., \& Herring, S. C. (2010). Functions of the Non-Verbal in CMC: Emoticons and illocutionary force. Communication Theory, 20, 249-268.

Drouin, M.A. (2011). College students' text messaging, use of textese and literacy skills. Journal of Computer Assisted Learning, 27, 67-75. doi: 10.1111/j.13652729.2010.00399.x 
Drouin, M., \& Davis, C. (2009). R u txting? Is the use of text speak hurting your literacy? Journal of Literacy Research, 41, 46-67. doi:10.1080/10862960802695131.

Drouin, M. \& Driver, B. (2012). Texting, textese and literacy abilities: A naturalistic study. Journal of Research in Reading. doi: 10.1111/j.1467-9817.2012.01532.x

Grace, A., Kemp, N., Martin, F. H., \& Parrila, R. (2013). Undergraduates' text messaging language and literacy skills. Reading and Writing.

Guron, L.M. (1999). Wordchains. London: NFER-Nelson.

Kemp, N. (2010). Texting vs. txtng: Reading and writing text messages, and links with other linguistic skills. Writing Systems Research, 2, 53-71. doi: 10.1093/wsr/wsq002

Kemp, N.M., \& Bryant, P. (2003). Do beez buzz? Rule-based and frequency-based knowledge in learning to spell plural -s. Child Development, 74 (1), 63-74. doi:10.1111/1467-8624.00521

Kreiner, D.S., \& Davis, D.L. (2011). Knowledge of text message abbreviations as a predictor of spelling ability. Perceptual and Motor Skills, 112(1), 295-309. doi: 10.2466/13.28.PMS.112.1.295-309

Lewis, C., \& Fabos, B. (2005). Instant messaging, literacies, and social identities. Reading Research Quarterly, 40, 470-501. doi:10.1598/RRQ.40.4.5

Massengill Shaw, D., Carlson, C., \& Waxman, M. (2007). An exploratory investigation into the relationship between text messaging and spelling. New England Reading Association Journal, 43, 57-62.

Mitchell, P., Kemp, N., \& Bryant, P. (2011). Variations among adults in their use of morphemic spelling rules and of word-specific knowledge when spelling. Reading Research Quarterly, 46, 119-133. doi:10.1598/RRQ.46.2.2 
Nunes, T., Bryant, P., \& Bindman, M. (1997). Morphological spelling strategies:

Developmental stages and processes. Developmental Psychology, 33(4), 637-649. doi: $10.1037 / 0012-1649.33 .4 .637$

Ofcom. (2011a). UK Children's media literacy. Retrieved from http://stakeholders.ofcom.org.uk/market-data-research/medialiteracy/medlitpub/medlitpubrss/ukchildrensml11/

Ofcom (2011b). A nation addicted to smartphones. Retrieved from http://media.ofcom.org.uk/2011/08/04/a-nation-addicted-to-smartphones/

Ofcom (2012a). Children and parents: Media use and attitudes report. Retrieved from http://stakeholders.ofcom.org.uk/binaries/research/media-literacy/oct2012/main.pdf

Ofcom (2012b). The communications market. Retrieved from http://stakeholders.ofcom.org.uk/binaries/research/cmr/cmr12/UK_1.pdf

Portio Research (2012). SMS is king of mobile messaging. Retrieved from http://mobithinking.com/mobile-marketing-tools/latest-mobile-stats/c

Plester B., Wood C., \& Bell V. (2008). Txt msg n school literacy: does texting and knowledge of text abbreviations adversely affect children's literacy attainment? Literacy, 42,137-144. doi: 10.1111/j.1741-4369.2008.00489.x.

Plester, B., Wood, C., \& Joshi, P. (2009). Exploring the relationship between children's knowledge of text message abbreviations and school literary outcomes. British Journal of Developmental Psychology, 27, 145-161. doi:10.1348/026151008X320507

Provine, R. R., Spencer, R. J., \& Mandell, D. L. (2007). Emotional expression online: Emoticons punctuate website text messages. Journal of Language and Social Psychology, 26, 299-307. 
Rosen, L. D., Chang, J., Erwin, L., Carrier, M., \& Cheever, N. A. (2010). The relationship between "textisms" and formal and informal writing among young adults. Communication Research, 37(3), 420-440. doi: 10.1177/0093650210362465

Tagliamonte, S.A., \& Denis, D. (2008). LINGUISTIC RUIN? LOL! Instant messaging and teen language. American Speech, 83 (1), 3-34. doi: 10.1215/00031283-2008-001

Taylor, A., and Vincent, J. (2005). An SMS history. In L. Hamill \& A. Lasen (eds), Mobile world: Past, present and future. (pp. 75-91). New York: Springer.

Thompson, B. (2003). Score reliability: Contemporary thinking on reliability issues. Thousand Oaks: Sage.

Thurlow, C. (2003). Generation txt? The sociolinguistics of young people's text-messaging. Discourse Analysis Online. Retrieved from tp://extra.shu.ac.uk/daol/articles/v1/n1/a3/thurlow2002003.html

Thurlow, C. (2006). From statistical panic to moral panic: The metadiscursive construction and popular exaggeration of new media language in the print media. Journal of Computer-Mediated Communication, 11, 667-701. doi: 10.1111/j.10836101.2006.00031.x

Varnhagen, C., McFall, P., Pugh, N., Routledge, L., Sumida-MacDonald, H., \& Kwong, T. (2009). lol: New language and spelling in instant messages. Reading and Writing, 23, 719-733. doi: 10.1007/s/11145-009-9181-y

Veater, H. M., Plester, B., \& Wood, C. (2011). Use of text message abbreviations and literacy skills in children with dyslexia. Dyslexia: An International Journal of Research and Practice, 17(1), 65-71. 10.1002/dys.406

Wechsler, D. (1999). Wechsler Abbreviated Scale of Intelligence (WASI). San Antonio: Harcourt Assessment Inc. 
Wilkinson, G.S., \& Robertson, G.J. (2006). Wide Range Achievement Test: Fourth Edition. Northumberland: Ann Arbor Publishers Ltd.

Wood, C., Jackson, E., Hart, L., Plester, B., \& Wilde, L. (2011). The effect of text messaging on 9- and 10-year-old children's reading, spelling and phonological processing skills. Journal of Computer Assisted Learning, 27, 28-36. doi: 10.1111/j.13652729.2010.00398.x

Wood, C., Kemp, N., \& Plester, B. (2014). Text messaging and literacy: The evidence. London: Routledge.

Wood, C., Meacham, S. Bowyer, S., Jackson, E. Tarczynski-Bowles, M.L., \& Plester, B. (2011). A longitudinal study of the relationship between children's text messaging and literacy development. British Journal of Psychology, 102, 431-442.

Woronoff, P. (2007). Cell phone texting can endanger spelling. Retrieved 10 January 2013 from: http://www.articlesbase.com/cell-phones-articles/call-phone-texting -canendanger-spelling-276413.html. 
Table 1: Grammatical Errors in Coded Messages

\begin{tabular}{|c|c|}
\hline Category of violation, and violation types & Example \\
\hline \multicolumn{2}{|l|}{ Unconventional Orthographic Forms } \\
\hline Ellipsis & $\ldots$ \\
\hline Start of sentence emoticon & :D Hi there! \\
\hline Start of sentence kiss & X love you \\
\hline End of sentence emoticon & () (instead of punctuation) \\
\hline End of sentence kiss & $\mathrm{X}$ (instead of punctuation) \\
\hline End of sentence initialism & LOL, LMAO (instead of punctuation) \\
\hline More than one question mark & Are you coming out later??? \\
\hline More than one exclamation mark & It was so awesome!!! \\
\hline More than one emoticon & ;: :D :x (instead of punctuation) \\
\hline More than one kiss & XXX (instead of punctuation) \\
\hline \multicolumn{2}{|l|}{ Incorrect Punctuation and Capitalisation } \\
\hline Mid sentence missing full stop/ comma & It was ace are you coming out later? \\
\hline End of sentence missing full stop & I am going out later \\
\hline Missing question mark & Are you coming out later \\
\hline i for I & i will be out later. \\
\hline Missing proper noun capitals & I am going to see tom tonight. \\
\hline Missing start of sentence capitals & it will be a great night. \\
\hline Missing contraction apostrophe & Im not coming out. \\
\hline Missing possession apostrophe & Robs books are blue. \\
\hline Unnecessary apostrophe & These shoe's are comfy \\
\hline \multicolumn{2}{|l|}{ Word error } \\
\hline Missing pronoun/subject & Am going out later \\
\hline Missing verb & I going out later. \\
\hline Missing function words (e.g., do, with) & You want to come with me? \\
\hline Missing word endings (e.g., -ed, -ing) & I am go to school. \\
\hline Missing other & $\begin{array}{l}\text { campin later (could be: are you camping } \\
\text { later? I am camping later, or I will see } \\
\text { you at camping later) }\end{array}$ \\
\hline Grammatical homonyms (e.g., & Their going to town too buy sweets. \\
\hline \multicolumn{2}{|l|}{ they're/their, you're/your) } \\
\hline Ungrammatical word forms & Does you want to go out later? \\
\hline Word/verb reduction & Tryna, hafta, wanna, gonna \\
\hline
\end{tabular}


Table 2: Mean Scores for Texting and Linguistic Measures, by Age Group (SD in Parentheses). * Indicates a Significant Main Effect of Age Group on that Variable at $p<.05$.

\begin{tabular}{|c|c|c|c|}
\hline Variable Name & Primary & Secondary & Adult \\
\hline & School & School & \\
\hline Age first phone acquired (years)* & $7.3(1.7)$ & $8.6(2.0)$ & $12.8(2.3)$ \\
\hline WASI IQ (Standard Score)* & $103.3(17.1)$ & $98.4(16.2)$ & $105.9(12.6)$ \\
\hline TROG (Standard Score)* & $91.2(13.1)$ & $92.0(16.1)$ & $96.6(13.7)$ \\
\hline WRAT Spelling (Standard Score*) & $104.7(12.9)$ & $103.3(11.8)$ & $108.8(16.8)$ \\
\hline Wordchains (Standard Score)* & $101.3(16.5)$ & $100.6(14.5)$ & $92.9(10.9)$ \\
\hline Orthographic Choice (max. 64)* & $37.9(6.5)$ & $39.4(8.6)$ & $53.3(8.9)$ \\
\hline Mean number of messages sent per day* & $3.9(3.0)$ & $4.2(2.9)$ & $9.6(4.6)$ \\
\hline \multicolumn{4}{|l|}{ Proportion of Grammatical Violations } \\
\hline Unconventional Orthographic Forms* & $.035(.113)$ & $.102(.118)$ & $.065(.046)$ \\
\hline Punctuation and Capitalisation Errors* & $.334(.237)$ & $.274(.170)$ & $.095(.089)$ \\
\hline Word-Based Grammatical Errors & $.129(.134)$ & $.143(.151)$ & $.081(.062)$ \\
\hline Overall & $.499(.294)$ & $.519(.230)$ & $.241(.123)$ \\
\hline
\end{tabular}


Table 3: Correlation Matrix Representing Pearson Correlation Coefficients between

Variables for the Primary School Sample $\left(\mathrm{N}=89,{ }^{*} p<.05, * * p<.01\right)$

\begin{tabular}{llllllllll}
\hline & IQ & TROG & WRAT & WC & OC & AgePhone & Txt/Day & UnOrth & Punc\&Cap \\
\hline TROG & $.403^{* *}$ & & & & & & & \\
WRAT & $.293^{* *}$ & $.308^{* *}$ & & & & & & \\
WC & $.336^{* *}$ & $.397^{* *}$ & $.531^{* *}$ & & & & & & \\
OC & $.504^{* *}$ & $.498^{* *}$ & $.349^{* *}$ & $.424^{* *}$ & & & & \\
AgePhone & .023 & .147 & -.158 & -.033 & -.009 & & & \\
Txt/Day & .018 & .082 & -.037 & .109 & .007 & -.032 & & \\
UnOrth & -.073 & -.029 & .065 & -.043 & -.066 & -.033 & -.051 & & \\
Punc\&Cap & -.037 & -.041 & -.185 & -.157 & -.050 & .059 & -.063 & -.089 & \\
WordErr & -.010 & -.063 & .102 & -.155 & -.187 & -.121 & .035 & -.123 & .125 \\
\hline
\end{tabular}

Key: $W R A T=$ WRAT Spelling subtest, $W C=$ Wordchains, $O C=$ Orthographic Choice Task, AgePhone $=$ Age participant received first phone, $T x t / D a y=$ Number of text messages sent per day, UnOrth = Unconventional Orthographic Forms; Punc\&Cap = Punctuation and Capitalisation Errors; WordErr = Word-Based Grammatical Errors 
Table 4: Correlation Matrix Representing Pearson Correlation Coefficients between Variables, for the Secondary School Sample $\left(\mathrm{N}=84,{ }^{*} p<.05,{ }^{* *} p<.01\right)$

\begin{tabular}{llllllllll}
\hline & IQ & TROG & WRAT & WC & OC & AgePhone & Txt/Day & UnOrth & Punc\&Cap \\
\hline TROG & $.311^{* *}$ & & & & & & & \\
WRAT & .152 & $.326^{* *}$ & & & & & & \\
WC & .172 & .049 & .133 & & & & & \\
OC & .189 & $.244^{* *}$ & $.330^{* *}$ & -.075 & & & & \\
AgePhone & .091 & -.118 & .092 & -.017 & .042 & & & \\
Txt/Day & .089 & .078 & .068 & .075 & -.073 & .081 & & & \\
UnOrth & $.216^{*}$ & .098 & .027 & .161 & -.003 & -.186 & -.175 & & \\
Punc\&Cap & -.125 & -.056 & -.107 & -.108 & .161 & .009 & .105 & $-.313^{* *}$ & \\
WordErr & -.149 & .020 & .186 & -.022 & -.010 & -.062 & -.115 & -.121 & .089 \\
\hline
\end{tabular}

Key: $W R A T=$ WRAT Spelling subtest, $W C=$ Wordchains, $O C=$ Orthographic Choice Task, AgePhone $=$ Age participant received first phone, $T x t /$ Day $=$ Numbers of text messages sent per day, UnOrth = Unconventional Orthographic Forms; Punc\&Cap = Punctuation and Capitalisation Errors; WordErr $=$ Word-Based Grammatical Errors 
Table 5: Correlation Matrix Representing Pearson Correlation Coefficients between

Variables, for the Adult Sample $\left(\mathrm{N}=70,{ }^{*} p<.05, * * p<.01\right)$

\begin{tabular}{llllllllll}
\hline & IQ & TROG & WRAT & WC & OC & AgePhone & Txt/Day & UnOrth & $\begin{array}{c}\text { Punc\& } \\
\text { Cap }\end{array}$ \\
\hline TROG & $.339^{* *}$ & & & & & & & & \\
WRAT & .179 & .110 & & & & & & & \\
WC & $.604^{* *}$ & .211 & $.386^{* *}$ & & & & & & \\
OC & $.451^{* *}$ & $.350^{* *}$ & .202 & $.387^{* *}$ & & & & & \\
AgePhone & $.289^{*}$ & .126 & .109 & .066 & .108. & & & \\
Txt/Day & -.118 & .022 & .169 & -.091 & -.151 & -.004 & & \\
UnOrth & .099 & .137 & .200 & .099 & .069 & -.014 & -.014 & & \\
Punc\&Cap & $-.338^{* *}$ & -.074 & -.194 & -.220 & $-.433^{* *}$ & -.113 & -.113 & $-.328^{* *}$ & \\
WordErr & .079 & .015 & -.078 & .030 & -.173 & .135 & -.078 & $.361^{* *}$ & -.038 \\
\hline
\end{tabular}

$W R A T=$ WRAT Spelling subtest,$W C=$ Wordchains, $O C=$ Orthographic Choice Task, AgePhone $=$ Age participant received first phone, $T x t /$ Day $=$ Numbers of text messages sent per day, UnOrth = Unconventional Orthographic Forms; Punc \&Cap = Punctuation and Capitalisation Errors; WordErr $=$ Word-Based Grammatical Errors 
Table 6: Summary of Multiple Regression Analysis of Adult Data

\begin{tabular}{llllll}
\hline Predictor Variables & $\boldsymbol{R}^{2}$ Change & F Change & Beta & $\boldsymbol{t}$ & $\boldsymbol{p}$ \\
\hline Step 1 Model & .219 & 9.389 & & & $<.0005$ \\
IQ & & & .429 & 3.908 & $<.0005$ \\
Spelling & & & .125 & 1.141 & .258 \\
Step 2 Model & .080 & 7.258 & & & .008 \\
Punctuation and & & & -.304 & 2.744 & .008 \\
Capitalisation Errors & & & & & \\
\end{tabular}




\section{Appendix: Orthographic Choice Task}

Version 1 of pseudowords presented in orthographic choice task, with spellings to suit grammatical status.

\begin{tabular}{|c|c|c|c|c|c|c|c|}
\hline & r nouns & Plur & nouns & Infir & e verbs & 3rd-pe & $\begin{array}{l}\text { on sing. } \\
\text { bs }\end{array}$ \\
\hline yox & preeze & quocks & spees & snox & troze & trocks & skoys \\
\hline thax & fooze & fracks & frues & drax & fize & gicks & glies \\
\hline zix & gruze & grecks & drues & blux & taze & yicks & drees \\
\hline brux & thaze & thocks & snays & swex & veeze & procks & voes \\
\hline Singu & uns & Past-tens & verbs & & nts & Supe & atives \\
\hline brold & tist & zored & yicked & vorcist & leebist & morpest & baipest \\
\hline lond & joft & relled & vossed & zarbist & fertist & boolest & coomest \\
\hline nard & shest & grenned & gocked & yintist & dorpist & shormest & tondest \\
\hline zund & hift & frelled & thupped & teffist & bilkist & maipest & parnest \\
\hline
\end{tabular}

